\title{
Key conclusions of the first international urban land surface model comparison project
}

Article

Accepted Version

Best, M. J. and Grimmond, C. S. B. (2015) Key conclusions of the first international urban land surface model comparison project. Bulletin of the American Meteorological Society, 96 (5). pp. 805-819. ISSN 1520-0477 doi:

https://doi.org/10.1175/BAMS-D-14-00122.1 Available at https://centaur.reading.ac.uk/37718/

It is advisable to refer to the publisher's version if you intend to cite from the work. See Guidance on citing.

Published version at: http://dx.doi.org/10.1175/BAMS-D-14-00122.1

To link to this article DOI: http://dx.doi.org/10.1175/BAMS-D-14-00122.1

Publisher: American Meteorological Society

All outputs in CentAUR are protected by Intellectual Property Rights law, including copyright law. Copyright and IPR is retained by the creators or other copyright holders. Terms and conditions for use of this material are defined in the End User Agreement.

www.reading.ac.uk/centaur 
Central Archive at the University of Reading

Reading's research outputs online 
1 Key conclusions of the first international urban land surface model comparison 2 project

3 M.J. Best, C.S.B. Grimmond

5

6

7 AFFILIATIONS: Best - Met Office, Exeter, UK, and King's College London,

8 London, UK; Grimmond - University of Reading, Reading, UK

9

10 CORRESPONDING AUTHOR: Martin J. Best, Met Office, FitzRoy Road, Exeter,

11 EX1 3PB, UK.

12 E-mail: martin.best@metoffice.gov.uk

13 
14 ABSTRACT: The first international urban land surface model comparison was designed to identify three aspects of the urban surface-atmosphere interactions: (1) the dominant physical processes, (2) the level of complexity required to model these, and (3) the parameter requirements for such a model. Offline simulations from 32 land surface schemes, with varying complexity, contributed to the comparison. Model results were analysed within a framework of physical classifications and over four stages. The results show that the following are important urban processes; (i) multiple reflections of shortwave radiation within street canyons, (ii) reduction in the amount of visible sky from within the canyon, which impacts on the net long-wave radiation, (iii) the contrast in surface temperatures between building roofs and street canyons, and (iv) evaporation from vegetation. Models that use an appropriate bulk albedo based on multiple solar reflections, represent building roof surfaces separately from street canyons and include a representation of vegetation demonstrate more skill, but require parameter information on the albedo, height of the buildings relative to the width of the streets (height to width ratio), the fraction of building roofs compared to street canyons from a plan view (plan area fraction) and the fraction of the surface that is vegetated. These results, whilst based on a single site and less than 18 months of data, have implications for the future design of urban land surface models, the data that need to be measured in urban observational campaigns, and what needs to be included in initiatives for regional and global parameter databases. 


\section{Capsule Summary}

The conclusions from the first international urban land surface model comparison project have implications for future models, observations and parameter databases, that extend beyond the urban modelling community

\section{Introduction}

Urban areas are often warmer than their surrounding rural environments, referred to as the urban heat island (UHI). This urban warming has numerous effects, including the initiation of convective storms (e.g., Bornstein and Lin, 2000), altering pollution dispersion by adapting mixing through changes to atmospheric boundary layer structure (e.g., Sarrat et al., 2006, Luhar et al., 2014), impacts on the production and mixing of ozone (e.g., Chaxel and Chollet, 2009, Ryu et al., 2013), enhanced energy demand for summer-time cooling through air conditioning (e.g., Radhi and Sharples, 2013, Li et al., 2014), impacts on urban ecology (e.g., Pickett et al., 2008, Francis and Chadwick, 2013) and increased mortality rates during heat waves (e.g., Laaidi et al., 2012, Herbst et al., 2014, Saha et al., 2014). As such, it is important to be able to accurately forecast urban warming and other meteorological variables for cities where the majority of the World's population now lives.

Predictions of future climate suggest additional warming in urban environments (McCarthy et al., 2010, Oleson et al., 2011). Indeed, the Inter-Governmental Panel on Climate Change (IPCC) Working Group 1 Fifth Assessment Report (IPCC, 2013) included at least one model that explicitly included an urban representation, and this number is likely to increase in the future as the resolution of these climate models increases to the extent that some urban areas are resolved. For future design of 
60 buildings and planning of cities, it is important that the dominant processes that lead

61 to urban warming effects are considered. This requires the development of models that can represent the most important features of the urban heat island be used for reliable predictions.

The urban heat island results from differences in surface energy exchanges between the urban environment and its surrounding rural area. Thus, understanding these differences is needed to interpret the urban heat island. The differences in urban surface energy exchanges arise through a number of processes. The geometry of a street canyon will increase the incoming solar radiation and long-wave radiation that are absorbed, due to multiple reflections and re-radiated from the 3-dimensional

71 structures. The orientation of street canyons and the elevation of the sun will impact

72 the reflected solar radiation, as a consequence of the depth to which the direct

73 sunshine can penetrate into the canyon. The reduced availability of water at the urban

74 surface, compared to natural vegetated or bare soil surfaces, means more of the

75 incoming solar radiation is transformed into heat rather than a flux of moisture into

76 the atmosphere. However, a larger proportion of this energy for heating is held within

77 the fabric of the buildings given the large thermal inertia of the materials, resulting in

78 changes in the diurnal cycle of urban temperatures. Moreover, an additional source of

79 heating within the urban areas comes from human activities such as transport, the

80 internal heating of the buildings and the metabolic rates of the people themselves

81 (e.g., Sailor and Lu, 2004).

83 All of these processes contribute to the differences in the energy balance between 84 urban and rural surfaces, but it is difficult to identify which are the dominant 
processes just from observations as the processes cannot be separated because of the complex nature of the environment. As such, the best way to study these processes individually is by using urban land surface models (ULSMs) that have been developed for weather and climate applications, i.e., exchange surface fluxes with an atmospheric model. There are a number of such ULSMs that vary considerably in their complexity (e.g., Kusaka et al., 2001, Fortuniak, 2003, Krayenhoff and Voogt, 2007, Hamdi and Masson, 2008, Lee and Park, 2008, Oleson et al., 2008a). Although newer models often include more complex features than previous models, without knowing the dominant processes and controls, it is difficult to quantify the impact of each new feature.

The first urban land surface model comparison was designed to objectively assess and compare the performance of a range of ULSMs for a single observational site. It attempted to identify the dominant physical processes that need to be represented in ULSMs by comparing models of varying complexity (Table 1). These models ranged from simple bulk representations of the surface that have been applied to atmospheric models for over a decade, representations of the facets of a street canyon (i.e., roofs, walls and road) that have been used in weather and climate models, through to more recently developed schemes that consider a complete energy balance at various levels within the urban canyon that have been applied to stand alone single point studies. Figure 1 shows a conceptual representation of the surface energy balance for these models of varying complexity. Whilst the scale that these models typically represent is larger than the size of the elements within a street canyon, a common feature is the ability to predict the exchange of fluxes between the urban surface and the atmosphere above it, i.e., the net all-wave radiation $\left(Q^{*}\right)$, turbulent sensible $\left(Q_{H}\right)$ and latent heat 
$110\left(Q_{E}\right)$ fluxes, as measured from flux towers in numerous urban observational

111 campaigns.

112 The aim of the urban model comparison was to consider:

113 (1) What are the dominant physical processes in the urban environment?

114 (2) What is the level of complexity required for an ULSM to be fit for purpose?

115 (3) What are the parameter requirements for such a model?

116 Here we present an analysis of the model comparison results to address these

117 questions.

1192 Model Comparison design

\section{$120 \quad 2.1$ Observational data}

121 The criteria for selecting the evaluation dataset were; first it had not been used to evaluate any ULSMs previously, and second it needed to cover an annual cycle to

123 allow assessment for different seasons. Model evaluation studies often result in the

124 development and optimisation of a model in order to obtain better representation of

125 the assessed metrics. Hence, using a dataset previously used by one or a sub-set of the

126 models to be evaluated would not enable a clean/independent objective assessment for

127 all of the models.

129 The dataset for a suburb of Melbourne (Preston) (Coutts et al., 2007a, 2007b) that had 130 observations from 13 August 2003 to 13 November 2004 was selected. The

131 moderately developed, low-density housing area is classified by Coutts et al. (2007b)

132 as an Urban Climate Zone (UCZ) 5 (Oke, 2006), Local Climate Zone (LCZ) 6

133 (Stewart and Oke, 2012) or Loridan and Grimmond (2012) Urban Zone for Energy

134 exchange (UZE) medium density. The description of UCZ 5 is "medium 
135 development, low density suburban with 1 or 2 storey houses, e.g., suburban housing”

136 (Oke, 2006), and as such the site is typical of suburban areas found in North America,

137 Europe and Australasia. The area has mean building height-to-width ratio of 0.42 and

138 mean wall-to-plan ratio of 0.4 (Coutts et al., 2007b). The surface is dominated by

139 impervious cover ( $44.5 \%$ buildings, $4.5 \%$ concrete and $13 \%$ roads), with a pervious

140 cover of $38 \%$ (15\% grass, $22.5 \%$ other vegetation and $0.5 \%$ bare ground or pools)

141 (Coutts et al., 2007a).

142

143 The methods used to obtain the observed fluxes applied to our current analysis are

144 given in Table 2, with details (e.g., data processing) presented in the original

145 observation papers (Coutts et al., 2007a, 2007b). In addition, the initial model

146 comparison results papers (Grimmond et al., 2011, Best and Grimmond, 2013, 2014)

147 provide the site parameters. A continuous gap-filled atmospheric forcing dataset (474

148 days) to run the models was created for this study (see Grimmond et al., 2011). To

149 evaluate the modelled fluxes (sensible heat flux, latent heat flux, net all-wave

150 radiative flux and net storage heat flux $\left.\left(\Delta Q_{S}\right)\right) 30 \mathrm{~min}$ periods are used when no

151 observed fluxes are missing to allow consistent analysis between the fluxes $(\mathrm{N}=8865$

152 or $38.9 \%$ of the full period).

153

$154 \quad 2.2$ Data analysis

155 To permit the research questions posed above to be considered, information about the

156 observational site was released to the modelling groups in stages. This enabled

157 analysis of the importance of the different types of information to model performance

158 through assessment of the change in model skill between the stages. The stages (Table

159 3), designed to correlate with ease of access to information for all cities globally, 
involved release of (Grimmond et al., 2011):

161 Stage 1: Atmospheric forcing data: (Table 3), typically provided by an atmospheric 162 model.

163 Stage 2: Vegetation and built fraction: two dimensional plan area characteristics of

164 the site. These can be determined from land cover datasets derived from satellite data.

165 Stage 3: Morphology: three dimensional characteristics of the site (Table 3.). These

166 can be interpreted from LiDAR (e.g., Goodwin et al., 2009, Lindberg and Grimmond,

167 2011), aerial photographs (e.g., Ellefsen, 1990/1991), detailed satellite imagery (e.g.,

168 Brunner et al., 2010), or simple empirical relations (e.g., Bohnenstengel et al., 2011).

169 Stage 4: Building material parameters (Table 3): only obtainable from local

170 knowledge of the materials used in the construction of the buildings.

171 Stage 5: Observed fluxes: to allow parameter optimisation studies. Only a few groups 172 completed this stage, so these results are not presented here.

174 The results from 24 modelling groups are analysed, involving 21 independent models

175 (Table 1). Alternative versions of the same model were run by the same or

176 independent modelling groups, which resulted in 32 sets of model simulations being

177 submitted for all of the four stages (see full list in Grimmond et al., 2011). Each group

178 completed a survey indicating the level of complexity used for various physical

179 processes within their models. From the latter, categories of physical processes were

180 established, with classes that cover the range of complexities (Grimmond et al., 2010,

181 2011). These categories were chosen to investigate the importance of various physical

182 processes that could contribute to differences in the surface energy balance between

183 the urban and rural environments. Thus every model is assigned to a class in each

184 category based on the survey information. In this study, the complexity category 
185 (Grimmond et al., 2011) is not considered as the focus is to separate the specific

186 physical processes. The categories, with the number of models in each class are

187 shown in Table 4.

188

189 Comparing the mean behaviour of the models in each of the classes as a reference

190 provides a method to determine the level of complexity that gives the best

191 performance for each category. These data are analysed to address the second research

192 question, where "fit for purpose" in this study is defined as being able to accurately

193 represent the energy exchange between the urban surface and the atmosphere (i.e., the

194 net all-wave radiation, turbulent sensible and latent heat fluxes).

195

196 Furthermore, by assessing the performance of the models across the categories for all

197 classes, it is possible to identify the physical processes that have the largest impact on

198 the performance of the models, hence identifying the dominant physical processes and

199 addressing the first research question.

\subsection{Methodology}

202 Initial results from the urban model comparison (Grimmond et al., 2011) ranked the

203 models and assessed the performance of the various classes within the categories

204 using standard statistical measures. Here an alternative approach to assess the models

205 performance is used, that considers the percentage of the models' data values that are

206 within observational error $\left(E_{o b s}\right)$. This gives a measure between zero (no values within

207 observational errors) and 100\% (all values within observational errors, i.e., a 'perfect'

208 model). Although this type of analysis is not strictly benchmarking, as each model is

209 not being compared to an a priori metric, it could be considered as being closer to the 
benchmarking ethos as having all data points within observational errors would be a

211 stringent metric.

213 The observational error estimates used in this analysis are for day-time fluxes based

214 on a percentage of the observed fluxes, as suggested by Hollinger and Richardson

215 (2005): net all-wave radiation flux 5\%, turbulent sensible heat flux 10\%, latent heat

216 flux 8\%, and upward components of both shortwave and long-wave radiation fluxes

$21710 \%$. As the net storage heat flux in the observational dataset is determined as the

218 residual of the surface energy balance, its observational error is assumed to be the sum

219 of the errors for the other terms (i.e., $Q^{*}, Q_{H}$ and $Q_{E}$ ), giving $23 \%$. The night-time

220 error estimates are assumed to be double the day-time error estimates for each of the

221 fluxes. The absolute magnitude of fluxes during this period are typically small (order

222 of $\left.(10) \mathrm{W} \mathrm{m}^{-2}\right)$, hence changes in the percentage of the observed flux used as the error

223 estimates are likely to be within the reporting resolution (e.g. order of (1) $\mathrm{W} \mathrm{m}^{-2}$ ) of

224 the observations (especially the turbulent fluxes). Whilst these error estimates may be

225 indicative rather than the actual values, the results would not substantially change the 226 analysis presented.

228 The analysis was undertaken for each model $(k)$ in each class $(j)$ within each category

229 (i) (Table 4), for each flux, over each stage within the comparison, and separately for 230 day-time and night-time. From this the percentage of data within observational error $231\left(E_{\text {obs } i, j}\right)$ was determined:

$$
E_{o b s, i j}=\frac{\sum_{k=1}^{n_{i j}} M_{k}}{n_{i j} T} \times 100 \%
$$

233 where $\mathrm{M}$ is the number of points within observational error for model $(k), n$ is the 
234 number of models and $T$ is the number of day-time or night-time points in the time 235 series as appropriate.

\section{Results}

238 Application of eqn. 1 to the sensible, latent and net storage heat fluxes, for each class 239 and category, at Stage 1 and Stage 4 (Table 3) are shown in Figure 2. The results 240 could range between $0 \%$ (i.e., no model data points within the observations errors) to

241 100\% (i.e., all model data points within observational errors). The relative changes

242 between the stages are also shown if Figure 2, i.e., for stage (s) the change relative to 243 the previous stage (s-1) given by:

$$
E_{o b s, i j}^{s} / E_{o b s, i j}^{s-1}
$$

245 Assessment of "between stages performance" allows an emphasis of the common

246 results across all of the classes and categories. It is scaled between 0\% and 100\%,

247 with $50 \%$ corresponding to no change between the stages (Figure 2).

249 Generally the results of the analysis, consistent with Grimmond et al. (2011), show that the skill to model latent heat fluxes is improved between stages 1 and 2. Knowing 251 the plan area vegetation fraction (provided in Stage 2) is important for modelling the 252 latent heat flux. No other stages show a general increase in model performance across 253 the classes and categories for the fluxes shown in Figure 2. For the radiation fluxes

254 (Fig. 3), the largest changes evident between Stages 3 and 4 are for the reflected 255 shortwave radiation flux and are due to the specification of the bulk albedo at the site 256 (i.e., the ratio of the reflected outgoing shortwave radiation flux from the whole urban 257 surface to the incoming shortwave radiation flux, information released at Stage 4). 258 This is also consistent with the conclusions from Grimmond et al. (2011). 
260 Model performance for the outgoing long-wave radiation flux has its largest changes

261 at night-time between Stages 3 and 4 (when the 3-d site morphological information

262 (Table 3) were made available, Fig. 3). This enhanced performance at night could be

263 related to improved estimates of the sky view factor which influences radiative

264 trapping, and/or from improved estimates of the difference in nocturnal surface

265 temperatures between building roofs and those of the roads and walls of the urban

266 canyons. Improved performance is not detected in the day-time outgoing long-wave

267 radiation flux (Fig. 3), probably because of the dominance of shortwave radiation at

268 this time. These results were not identified in Grimmond et al. (2011) as there was no

269 separate analysis for day-time and night-time.

271 It is evident from Figures 2 and 3 that the performance of the models for each of the

272 fluxes does not improve consistently for each stage, as might be expected. This

273 suggests that the models are not able to correctly make use of all of the information

274 that is provided at each of the stages and hence the design of the models, and the use

275 of their specific parameters, is not necessarily correct. This is discussed further in

276 Grimmond et al. (2011).

278 Each model is assigned to one class for every category (Table 4). This means that a

279 model with particularly good (or poor) performance will influence the results for its

280 class in each of the categories. The implications of this are that it is not possible to

281 ensure that the good performance from a particular class within one category is not

282 actually resulting from the results of a class from a different category. This potential

283 contamination of results by categories inhibits the analysis of the dominant physical 
processes and the suitability of the models. Both the analysis presented in Grimmond et al. (2011) and that in Figures 2 and 3 have this limitation, hence we will not consider further any results in Figures 2 and 3 for any specific class or category. Alternatively, to address this issue of cross-contamination, we repeat the complete analysis using eqn. 1 separately for each category (c), but only considering the subset 289 of models from class $(a)$. Hence for each class $(j)$ in category $(i)$ for the analysis of eqn. 1 , the models used are those that are in both class $(a)$ of category $(c)$ and class $(j)$

291 of category $(i)$, of which there are $n_{\alpha}=n_{c a} \cap n_{i j}$, thus:

$E_{o b s, c a i j}=\frac{\sum_{k=1}^{n_{\alpha}} M_{k}}{n_{\alpha} T} \times 100 \%$

293 This gives the equivalent of 26 versions of Figures 2 and 3 (one for each class in each category); although for a given subset of models it is inevitable that some classes will not have any members and hence have no data. We then apply the following equation

296 for each of the stages to determine which of the original class of models has the best 297 performance:

$298 \quad P_{c a}=\frac{\sum N_{m}}{N_{t o t}-\left(\sum N_{n d}\right)-1} \times 100 \%$

299 where $P_{c a}$ is the percentage of classes in the analysis that are improved from just the 300 subset of models (compared to the analysis with the full set of models),

$301 \quad N_{m}=\sum_{k=1}^{N_{b o t}}\left\{\begin{array}{l}1 \text { if } E_{o b s, c a i j}>E_{o b s, i j} \\ 0 \text { otherwise }\end{array}\right.$

302 is the number of classes that are improved in the analysis, $N_{t o t}$ is the total number of

$303 \operatorname{classes}\left(\sum i j=26\right)$ and 304

$$
N_{n d}=\sum_{k=1}^{N_{t o t}}\left\{\begin{array}{l}
1 \text { if } n_{c a} \bigcap n_{i j}=0 \\
0 \text { otherwise }
\end{array}\right.
$$


is the number of classes with no data.

307 Hence values of $P_{c a}$ close to $100 \%$ relate to nearly all classes in all categories being 308 improved from the physical process represented in class (a) of category (c). This

309 indicates that this process and its representation are important to model performance.

310 Whereas values close to $0 \%$ relate to almost all classes in all categories being

311 degraded, suggesting that the representation of the physical process is detrimental to

312 model performance. Values around 50\% have a similar number of classes that are 313 improved and degraded, suggesting that the representation of the physical process has

314 little impact on model performance. Hence the conclusions that can be drawn from 315 this analysis are more robust than those of Figures 2 and 3, and the previous study of 316 Grimmond et al. (2011).

318 For example, with models that have an infinite number of reflections (category R, 319 class i), the median of the results over the stages give a value of $88 \%$ for the night320 time net storage heat flux (Fig. 4). This results from 14 of the 16 possible classes 321 containing data being improved when considering only these models, demonstrating 322 that this is important for predicting this flux. However, models that have multiple 323 reflections (category $\mathrm{R}$, class $\mathrm{m}$ ) have a value of $12.5 \%$ for the night-time net storage 324 heat flux (Fig. 4). This results from only two of the possible 16 classes containing data 325 being improved, hence showing that this is detrimental to predicting the flux.

327 The results of Figure 4 show that for some classes (e.g., infinite reflections; category 328 R, class I, Table 4), there are some demonstrated improvements to a flux (e.g., LW up) 329 which is not obviously explained by the physics (e.g., how do infinite reflections of 
330 shortwave radiation improve the outgoing long-wave radiation but not the reflected

331 shortwave?). Also, there are some classes that improve one particular flux, but not

332 other fluxes. For example, models that represent the net storage heat flux as the

333 residual of the surface energy balance (category S, class r, Table 4) demonstrate a

334 clear improvement for the day-time sensible heat flux, but not for the latent or the net

335 storage heat fluxes. This could be because with such models the sensible heat flux is

336 not constrained by the energy balance giving them the freedom to enable better

337 predictions of the sensible heat flux, whilst moisture availability is still the main

338 control for the latent heat flux.

340 There are many such conclusions that can be drawn from Figure 4. Here the focus is

341 on results that are consistent between the fluxes, or consistent for a particular flux

342 between the day-time and night-time.

344 Models with a bulk representation of the albedo and emissivity (category $A_{E}$, class 1,

345 Table 4), and a bulk representation of facets and orientation (category $\mathrm{F}_{\mathrm{O}}$, class 1; the

346 models in these two classes were identical), demonstrate an improvement in skill

347 during the day-time for nearly all fluxes, with the exceptions of the outgoing long-

348 wave radiation which shows little change in skill and net all-wave radiation fluxes

349 with only small improvements (Fig. 4). This class of models also shows an

350 improvement in the night-time sensible and latent heat fluxes, but degradation in the

351 radiative fluxes during the night. These improved results are most likely due to the

352 ability to utilize the observed bulk albedo directly. This class of models clearly

353 delivers the largest benefits across the fluxes and indicates the most significant

354 physical process to represent is the bulk albedo for the urban surface, because the net 
355 shortwave radiation dominates the surface energy balance.

357 Improvements to the outgoing long-wave radiation flux and the net all-wave radiation

358 flux during both day-time and night-time are obtained from models that have a single

359 layer for each element of the urban environment (i.e., roofs and either urban canyons,

360 or walls and roads separately) in the morphology category (category L, class 2, Table

3614 4; Fig. 4). Improvements to the night-time sensible heat flux and net storage heat flux

362 are also obtained from this class of models, but there is no improvement to these

363 fluxes during the day-time. This neutral day-time result in the sensible and net storage

364 heat fluxes may be explained by the negative impact on the outgoing shortwave

365 radiation flux, which dominates over the long-wave radiation flux during the day-

366 time. However, these results demonstrate the importance of presenting the difference

367 in radiative surface temperatures between the roofs and the urban canyon, due to the

368 non-linear relationship between the upward long-wave radiation and the radiative

369 temperature.

371 When considering the way in which the models represent vegetation (category V,

372 Table 4), we find that although including vegetation (classes s and i, Table 4) does

373 generally lead to an improvement for the fluxes, these improvements are not as

374 obvious as those from the bulk albedo or the single layer urban morphology. Hence

375 although these results confirm those presented in earlier studies on the comparison

376 (Grimmond et al., 2011, Best and Grimmond, 2013, 2014), that representing

377 vegetation gives improved results, we demonstrate that the more robust analysis

378 presented here shows that this is not the most important physical process as was

379 concluded in these earlier studies. Getting the radiative fluxes correct from the 
shortwave via the bulk albedo and the long-wave through the urban morphology are

381 required before the vegetation can influence the partitioning of energy between the sensible and latent heat fluxes.

Previous studies on the urban comparison data have also concluded that models which neglect the anthropogenic heat flux $\left(\mathrm{Q}_{\mathrm{F}}\right)$ do at least as well as the models that include this flux, although they were unable to explain this result (Grimmond et al., 2011, Best and Grimmond, 2013, 2014). However, the results in Figure 4 show that although the class of models that neglect the anthropogenic heat flux (category $A_{N}$, class n, Table 4) do improve some of the fluxes, the improvements are not consistent over all of the fluxes. Moreover, this class of models within the anthropogenic heat

391 flux category is not always the one that delivers the best results. Hence we can conclude that although the models that neglect the anthropogenic heat flux do show some improved results, we cannot make any significant statements about the classes

394 within this category.

\section{Conclusions}

397 Prior conclusions from the ULSM comparison with daily (24 h) and seasonal analysis 398 include that: representation of vegetation is critical to model performance (Grimmond 399 et al., 2011, Best and Grimmond, 2013), along with the associated initial soil moisture 400 (Best and Grimmond, 2014), and the bulk albedo is also important (Grimmond et al., 401 2011). Notably, neglecting the distinctive urban anthropogenic heat flux was not 402 found to penalize performance (albeit in the suburban area the value is small) (Best 403 and Grimmond, 2013). However, this new analysis considering diurnal performance 404 (day, night) enables us to conclude that nocturnal radiative processes also benefit from 
accounting for the enhanced long-wave trapping that occurs within urban areas.

406 Separating the radiative processes of the roof and the urban canyon is beneficial.

408 More critically, the more robust analysis presented here enables identification of a re-

409 prioritisation of the key physical processes: firstly, ensuring the use of the correct bulk

410 albedo for the urban surface; secondly, the outgoing long-wave radiative fluxes with

411 the representation of morphology separated into roofs and urban canyons; and thirdly,

412 the inclusion of vegetation. The implications of the bulk albedo is important for

413 observations as the temporal resolution of satellite estimates mean they will not

414 provide the variations by time of day that are observed (e.g., Christen and Voogt,

415 2004, Grimmond et al. 2004, Kotthaus and Grimmond 2014).

417 The current results for anthropogenic heat flux are consistent with the earlier studies:

418 that neglect of the relatively small magnitude flux at this site (study period mean $=$

$419 \sim 17 \mathrm{~W} \mathrm{~m}^{-2}$ ) is reasonable. This conclusion could well be different for urban

420 environments where this is a more significant term in the surface energy balance. The

421 flux is expected to be larger in other areas of Melbourne (e.g., as suggested from

422 analysis using the model of Lindberg et al. 2013) and for urban areas elsewhere. We

423 therefore recommend that future model comparisons ideally include areas of cities

424 with larger anthropogenic heat fluxes.

426 Thus to answer the three over-arching research questions of the urban model

427 comparison:

428 (i) The dominant physical processes in the urban environment that models need to be

429 able to simulate, in order, are; changes to the bulk albedo of the surface that result 
430 from building materials and also shortwave trapping from the canyon geometry; the 431 reduction in outgoing long-wave radiation from the street canyon due to a reduced 432 sky view factor and the contrast between this and the roofs that see a full sky view; 433 and the evaporation from vegetation.

434 (ii) For the current generation of ULSMs, the ability to utilize a bulk surface 435 albedo (category $A_{E}$, class 1 , Table 4) and to be able to distinguish between the 436 roofs of buildings and the urban canyons (category L, class 2), and to have a 437 representation of vegetation (category $\mathrm{V}$, classes $\mathrm{s}, \mathrm{i}$ ), results in the best 438 performance.

439 (iii) The key parameters for ULSMs are the bulk surface albedo (information given 440 for Stage 4 influencing the upward shortwave radiation flux), the height to width 441 ratio of the urban canyons and the fraction of building roofs to the urban canyons 442 (information given for Stage 3 influencing the upward long-wave radiation flux), 443 and the vegetation fraction (information given for Stage 2 influencing the sensible 444 and latent heat fluxes).

446 The results, from this and the previous studies on the ULSM comparison, all suggest 447 that a simple representation for most of the physical categories is sufficient for this 448 type of application, i.e., determination of local scale fluxes (e.g. for use in the 449 coupling to an atmospheric model). The prior categorization of the models 450 (Grimmond et al., 2011, Best and Grimmond, 2013) into (simple, medium and 451 complex) complexity classes based upon the number of physical categories treated as 452 simple by a model demonstrated that the simple models performed best. This relative 453 success of simple models suggests that for simulating local scale fluxes, more 454 complex schemes deliver little additional benefit. Furthermore, the reduced parameter 
requirements for simple schemes are advantageous for large scale applications, such as global or regional scale modelling. However, it cannot be expected that this conclusion would also hold for other applications, e.g., atmospheric dispersion within street canyons of a specific city, as the simple models do not present some of the basic physical requirements for such applications. Thus the requirement for the

460 development of more complex ULSMs does remain.

The implications of this study go beyond the urban environment. In general, we need to balance the requirement for complexity within models against what is actually required for a model to be fit for purpose. Hence new and more complex processes

465 should not be included in models unless it can be demonstrated that they are required.

466 In addition, consideration needs to be given to the availability of information to 467 specify parameters within complex models, and if such complexity can be justified 468 given the uncertainty range for the parameters. Also, the type of analysis used here 469 could be applied to any comparison study to ensure that the results are robust and not 470 contaminated by physical processes not being directly considered.

472 These key conclusions are based on the single site observational dataset of less than 47318 months. This suburban site of low density housing, is typical of extensive areas in 474 North America, Europe and Australasia. Hence we might expect the results from this 475 study to be valid over a reasonable range of cities. However, most urban environments 476 have a range of zones (e.g. Ellefsen, 1991, Grimmond and Souch, 1994, Stewart and 477 Oke, 2012) with very different characteristics. So to test if the results presented here 478 are robust for other cities, similar "experiments" are required for additional sites with 
differing climates and urban characteristics. Hence we recommend that further model comparison projects are required for the urban community.

Despite these limitations, the results have implications for future development of ULSMs and for the types of data that need to be collected in future urban measurement campaigns (e.g., soil moisture, given its impact to limit transpiration and the long timescales required for model spin-up, along with the conclusion that the fraction of vegetation is important for urban areas) and/or the parameters that should be collated systematically for cities around the world (e.g., Ching et al., 2009, Loridan and Grimmond, 2012, Stewart and Oke, 2012, Ching, 2013, Faroux et al., 2013).

Acknowledgements Funds to support the comparison project were provided by the Met Office (P001550). M. Best was supported by the Joint DECC/Defra Met Office Hadley Centre Climate Programme (CA01101). We would like to thank Andrew Coutts and Jason Beringer for allowing their data to be used for the comparison. We would also like to thank Mathew Blackett for all of his efforts in coordinating the model data collection, and to everyone who contributed results to the comparison from their models: J.-J. Baik, S.E. Belcher, J. Beringer, S.I. Bohnenstengel, I. Calmet, F. Chen, A. Dandou, K. Fortuniak, M.L. Gouvea, R. Hamdi, M. Hendry, M. Kanda, T. Kawai, Y. Kawamoto, H. Kondo, E.S. Krayenhoff, S.-H. Lee, T. Loridan, A. Martilli, V. Masson, S. Miao, K. Oleson, R. Ooka, G. Pigeon, A. Porson, Y.-H. Ryu, F. Salamanca, G.J. Steeneveld, M. Tombrou, J.A. Voogt, D.T. Young and N. Zhang. 


\section{References}

505

506 Best, M.J. (2005), Representing urban areas within operational numerical weather 507 prediction models. Boundary-Layer Meteorol, 114: 91-109.

508 Best M.J., C.S.B. Grimmond, M.G. Villani (2006), Evaluation of the urban tile in 509 MOSES using surface energy balance observations. Boundary-Layer Meteorol, $510 \quad 118: 503-525$.

511 Best M.J., M. Pryor, D.B. Clark, G.G. Rooney, R.H.L. Essery, C.B. Ménard, J.M.

512 Edwards, M.A. Hendry, A. Porson, N. Gedney, L.M. Mercado, S. Sitch, E. Blyth,

513 O. Boucher, P.M. Cox, C.S.B. Grimmond, R.J. Harding (2011) The Joint UK Land

514 Environment Simulator (JULES), Model description - Part 1: Energy and water $515 \quad$ fluxes. Geosci Model Dev, 4: 677-699

516 Best, M.J., C.S.B. Grimmond (2013), Analysis of the seasonal cycle within the first 517 international urban land surface model comparison, Boundary-Layer Meteorol., $518 \quad$ 146, 421-446, doi: 10.1007/s10546-012-9769-7.

519 Best, M.J., C.S.B. Grimmond (2014), Importance of initial state and atmospheric 520 conditions for urban land surface models performance, Urban Climate. In press, 521 doi:10.1016/j.uclim.2013.10.006

522 Bohnenstengel, S.I., S. Evans, P.A. Clark, S.E. Belcher (2011), Simulations of the 523 London urban heat island, Q. J. R. Meteorol. Soc., 137, 1625-1640, doi: $524 \quad 10.1002 / q j .855$.

525 Bornstein, R., Q. Lin (2000), Urban heat islands and summertime convection 526 thunderstorms in Atlanta: three case studies, Atmos. Environ., 34, 507-516, 527 doi:10.1016/S1352-2310(99)00374-X. 
528 Brunner, D., G. Lemoire, L. Bruzzone, H. Greidonus (2010), Building height retrieval 529 from VHR SAR imagery based on an iterative simulation and matching technique.

$530 \quad$ IEEE Transactions on Geoscience and Remote Sensing, 48, No.3, 531 doi:10.1109/TGRS.2009.2031910.

532 Chaxel, E., J.-P. Chollet (2009), Ozone production from Grenoble city during the 533 August 2003 heat wave, Atmos. Environ., 43, 4784-4792, 534 doi:10.1016/j.atmosenv.2008.10.054.

535 Chen F., H. Kusaka, M. Tewari, J. Bao, H. Hirakuchi (2004), Utilizing the coupled 536 WRF/LSM/Urban modeling system with detailed urban classification to simulate 537 the urban heat island phenomena over the Greater Houston area. Fifth Symposium 538 on the Urban Environment, CD-ROM. 9.11. Amer. Meteor. Soc., Vancouver, BC, 539 Canada.

540 Ching, J.K.S. (2013), A perspective on urban canopy layer modelling for weather, 541 climate and air quality applications, Urban Climate, 3, 13-39.

542 Ching, J., M. Brown, S. Burian, F. Chen, R. Cionco, A. Hanna, T. Hultgren, T.

543 McPherson, D. Sailor, H. Taha, D. Williams (2009), National urban database and 544 access portal tool, Bull. American Meteorol. Soc., 90, 1157-1168, 545 doi:10.1175/2009BAMS2675.1.

546 Christen, A., R. Voogt (2004), Energy and radiation balance of a central European 547 city, Int. J. Climatol., 24, 1395-1421, doi:10.1002/joc.1074.

548 Coutts, A.M., J. Beringer, N.J. Tapper (2007a), Characteristics influencing the 549 variability of urban CO2 fluxes in Melbourne, Australia, Atmos. Environ., 41, 51$550 \quad 62$. 
551 Coutts, A.M., J. Beringer, N.J. Tapper (2007b) Impact of increasing urban density on 552 local climate: spatial and temporal variations in the surface energy balance in 553 Melbourne, Australia, J. Appl. Meteorol., 47, 477-493.

554 Dandou A., M. Tombrou, E. Akylas, N. Soulakellis, E. Bossioli (2005), Development 555 and evaluation of an urban parameterization scheme in the Penn State/NCAR $556 \quad$ Mesoscale model (MM5). J Geophys Res, 110: D10102. doi:10.1029/2004JD005192.

558 Dupont S., P.G. Mestayer (2006), Parameterisation of the urban energy budget with 559 the submesoscale soil model. J Appl Meteorol Climatol, 45: 1744-1765.

560 Dupont S., P.G. Mestayer, E. Guilloteau, E. Berthier, H. Andrieu (2006),

561 Parameterisation of the urban water budget with the submesoscale soil model. $J$ 562 Appl Meteorol Climatol, 45: 624-648.

563 Ellefsen, R. (1991), Mapping and measuring buildings in the canopy boundary layer 564 in ten U.S. cities. Energy and Buildings, 16, 1025-1049.

565 Essery R.L.H., M.J. Best, R.A. Betts, P.M. Cox, C.M. Taylor (2003), Explicit 566 representation of subgrid heterogeneity in a GCM land surface scheme. $J$ $567 \quad$ Hydrometeorol, 4: 530-543.

568 Faroux, S., A. T. Kaptue Tchuente, J.-L. Roujean, V. Masson, E. Martin, P. Le 569 Moigne (2013), ECOCLIMAP-II/Europe: a twofold database of ecosystems and 570 surface parameters at $1 \mathrm{~km}$ resolution based on satellite information for use in land 571 surface, meteorological and climate models, Geosci. Model Dev., 6, 563-582, 572 doi:10.5194/gmd-6-563-2013.

573 Fortuniak, K. (2003), A slab surface energy balance model (SUEB) and its application 574 to the study on the role of roughness length in forming an urban heat island. Acta 575 Universitatis Wratislaviensis, 2542, 368-377. 
576 Fortuniak K., B. Offerle, C.S.B. Grimmond (2004), Slab surface energy balance

577 scheme and its application to parameterisation of the energy fluxes on urban areas.

578 NATO ASI, Kiev, Ukraine; 82-83. Available from: www.met.rdg.ac.uk/urb

579 met/NATO ASI/talks.html (Last accessed 4-15 May 2010).

580 Fortuniak K., B. Offerle, C.S.B. Grimmond (2005), Application of a slab surface

581 energy balance model to determine surface parameters for urban areas. Lund

$582 \quad$ Electronic Reports in Physical Geography, 5: 90-91.

583 Francis, R.A., M.A. Chadwick. (2013), Urban Ecosystems: Understanding the Human $584 \quad$ Environment. Routledge, 220pp.

585 Goodwin, N.R., N.C. Coops, T.R. Tooke, A. Christen, J.A. Voogt (2009),

586 Characterizing urban surface cover and structure with airborne lidar technology. 587 Can. J. Remote Sens., 35, 297-309.

588 Grimmond, C.S.B., C. Souch (1994), Surface description for urban climate studies: a

589 GIS based methodology. Geocarto. International, 9, 47-59.

590 Grimmond C.S.B., T.R. Oke (2002), Turbulent heat fluxes in urban areas:

591 observations and local-scale urban meteorological parameterization scheme 592 (LUMPS). J Appl Meteorol, 41: 792-810.

593 Grimmond, C.S.B., J.A. Salmond, T.R. Oke, B. Offerle, A. Lemonsu (2004), Flux and 594 turbulence measurements at a densely built-up site in Marseille: Heat, mass (water 595 and carbon dioxide), and momentum. J. Geophys. Res. Atmos., 109, D24101, 596 doi:10.1029/2004jd004936

597 Grimmond, C.S.B., M. Blackett, M.J. Best, J. Barlow, J.-J. Baik, S.E. Belcher, S.I.

598 Bohnenstengel, I. Calmet, F. Chen, A. Dandou, K. Fortuniak, M.L. Gouvea, R.

599 Hamdi, M. Hendry, T. Kawai, Y. Kawamoto, H. Kondo, E.S. Krayenhoff, S.-H.

600 Lee, T. Loridan, A. Martilli, V. Masson, S. Miao, K. Oleson, G. Pigeon, A. 
601 Porson, Y.-H. Ryu, F. Salamanca, L. Shashua-Bar, G.-J. Steeneveld, M. Trombou,

602 J. Voogt, D. Young, N. Zhang (2010), The international urban energy balance

603 models comparison project: first results from phase 1, J. Appl. Meteorol.

604 Climatol., 49, 1268-1292, doi: 10.1175/2010JAMC2354.1.

605 Grimmond, C.S.B., M. Blackett, M.J. Best, J.-J. Baik, S.E. Belcher, J. Beringer, S.I.

606 Bohnenstengel, I. Calmet, F. Chen, A. Coutts, A. Dandou, K. Fortuniak, M.L.

607 Gouvea, R. Hamdi, M. Hendry, M. Kanda, T. Kawai, Y. Kawamoto, H. Kondo,

608 E.S. Krayenhoff, S.-H. Lee, T. Loridan, A. Martilli, V. Masson, S. Miao, K.

609 Oleson, R. Ooka, G. Pigeon, A. Porson, Y.-H. Ryu, F. Salamanca, G.-J.

610 Steeneveld, M. Trombou, J. Voogt, D. Young, N. Zhang (2011), Initial results

611 from phase 2 of the international urban energy balance model comparison, Int. $J$.

612 Climatol., 30, 244-272, doi:10.1002/joc.2227.

613 Hamdi, R., V. Masson (2008), Inclusion of a drag approach in the Town Energy

614 Balance (TEB) scheme: offline 1-D evaluation in a street canyon, J. Appl.

615 Meteorol. Climatol., 47, 2627-2644.

616 Harman I.N., M.J. Best, S.E. Belcher (2004a), Radiative exchange in an urban street 617 canyon. Boundary-Layer Meteorol, 110: 301-316.

618 Harman I.N., J.F. Barlow, S.E. Belcher (2004b), Scalar fluxes from urban street

619 canyons. Part II: model. Boundary-Layer Meteorol, 113: 387-410.

620 Harman I.N., S.E. Belcher (2006), The surface energy balance and boundary layer

621 over urban street canyons. Q J R Meteorol Soc, 132: 2749-2768.

622 Herbst, J., K. Mason, R.W. Byard, J.D. Bilbert, C. Charlwood, K.J. Heath, C.

623 Winskog, N.E.I. Langlois (2014), Heat-related deaths in Adelaide, South Australia:

624 Review of the literature and case findings - An Australian perspective, J. Forensic

$625 \quad$ and Legal Medicine, 22, 73-78. doi:10.1016/j.jflm.2013.12.018 
626 Hollinger, D.Y., A.D. Richardson (2005), Uncertainty in eddy covariance

627 measurements and its application to physiological models, Tree Physiol., 25, 873-

$628 \quad 885$.

629 IPCC (2014), Working Group I Contribution to the IPCC Fifth Assessment Report

630 (AR5), Climate Change 2013: The Physical Science Basis. Intergovernmental

$631 \quad$ Panel on Climate Change, Geneva, Switzerland.

632 Kanda M., T. Kawai, M. Kanega, R. Moriwaki, K. Narita, A. Hagishima (2005a), A

633 simple energy balance model for regular building arrays. Boundary-Layer

634 Meteorol, 116: 423-443.

635 Kanda M., T. Kawai, K. Nakagawa (2005b), A simple theoretical radiation scheme

636 for regular building arrays. Boundary-Layer Meteorol, 114: 71-90.

637 Kawai T., M. Kanda, K. Narita, A. Hagishima (2007), Validation of a numerical

638 model for urban energy-exchange using outdoor scalemodel measurements. Int $J$

639 Climatol, 27: 1931-1942.

640 Kawai T., M.K. Ridwan, M. Kanda (2009), Evaluation of the simple urban energy

641 balance model using 1-yr flux observations at two cities. J Appl Meteorol Climatol, $642 \quad 48: 693-715$.

643 Kawamoto Y., R. Ooka (2006), Analysis of the radiation field at pedestrian level

644 using a meso-scale meteorological model incorporating the urban canopy model. In

645 ICUC-6, Göteborg, Sweden, 12-16 June 2006.

646 Kawamoto Y., R. Ooka (2009a), Accuracy validation of urban climate analysis model

647 using MM5 incorporating a multi-layer urban canopy model. In ICUC-7,

648 Yokohama, Japan, 28 June-3 July 2009. 
649 Kawamoto Y., R. Ooka (2009b) Development of urban climate analysis model using

650 MM5 Part 2 - incorporating an urban canopy model to represent the effect of

651 buildings. J Environ Eng (Transactions of AIJ) 74(642): 1009-1018 (in Japanese).

652 Kondo H., F.H. Liu (1998), A study on the urban thermal environment obtained

653 through a one-dimensional urban canopy model, J Jpn Soc Atmos Environ. 33,

$654 \quad 179-192$ (in Japanese)

655 Kondo H., Y. Genchi, Y. Kikegawa, Y. Ohashi, H. Yoshikado, H. Komiyama (2005),

656 Development of a multi-layer urban canopy model for the analysis of energy

657 consumption in a big city: structure of the urban canopy model and its basic

658 performance. Boundary-Layer Meteorol, 116: 395-421.

659 Kotthaus, S., C.S.B. Grimmond (2013), Energy exchange in a dense urban

660 environment - Part II: Impact of spatial heterogeneity of the surface, Urban

661 Climate, hppt://dx.doi/org/10.1016/j.uclim.2013.10.001.

662 Krayenhoff, E.S., J.A. Voogt (2007), A microscale three-dimensional urban energy

663 balance model for studying surface temperatures, Boundary-Layer Meteorol., 123,

$664 \quad 433-461$.

665 Kusaka, H., H. Kondo, Y. Kikegawa, F. Kimura (2001), A simple singlelayer urban

666 canopy model for atmospheric models: comparison with multi-layer and slab

667 models, Boundary-Layer Meteorol., 101, 329-358.

668 Laaidi, K., A. Zeghnoun, B. Dousset, P. Bretin, S. Vandentorren, E. Giraudet, P.

669 Beaudeau (2012), The impact of heat islands on mortality in Paris during the

670 August 2003 heat wave, Environ. Health Perspectives, 120, 254-259,

671 doi:10.1289/ehp.1103532.

672 Lee, S.-H., S.-U. Park (2008), A vegetated urban canopy model for meteorological

673 and environmental modelling, Boundary-Layer Meteorol., 126, 73-102. 
674 Lemonsu A., C.S.B. Grimmond, V. Masson (2004), Modelling the surface energy

675 balance of an old Mediterranean city core. J Appl Meteorol, 43: 312-327.

676 Li, C.B., J.J. Zhou, Y.J. Cao, J. Zhong, Y. Liu, C.Q. Kang, Y. Tan (2014), Interaction

677 between urban microclimate and electric air-conditioning energy consumption

678 during high temperature season, Applied Energy, 117, 149-156,

679 doi:10.1016/j.apenergy.2013.11.057.

680 Lindberg, F., C.S.B. Grimmond (2011), Nature of vegetation and building

681 morphology characteristics across a city: Influence on shadow patterns and mean

682 radiant temperatures in London. Urban Ecosyst., 14, 617-623. doi:10.1007/s11252-

$683 \quad 011-0184-5$.

684 Lindberg, F., C.S.B. Grimmond, N. Yogeswaran, S. Kotthaus, L. Alen (2013),

685 Impacts of city changes and weather on anthropogenic heat flux in Europe 1995-

686 2015, Urban Climate, 4, 1-15. http://dx.doi.org/10.1016/j.uclim.2013.03.002.

687 Loridan T., C.S.B. Grimmond, S. Grossman-Clarke, F. Chen, M. Tewari, K.

688 Manning, A. Martilli, H Kusaka, M. Best (2010), Trade-offs and responsiveness of

689 the single-layer urban canopy parameterization in WRF: an offline evaluation

690 using the MOSCEM optimization algorithm and field observations. Q J R Meteorol

691 Soc, 136: 997-1019. doi:10.1002/qj.614.

692 Loridan T., C.S.B. Grimmond, B.D. Offerle, D.T. Young, T. Smith, L. Järvi, F.

693 Lindberg (2011), Local-scale urban meteorological parameterization scheme

694 (LUMPS): Longwave radiation parameterization and seasonality-related

695 developments. J Appl Meteorol Climatol, 50: 185-202.

696 doi:10.1175/2010JAMC2474.1 

model: intra-urban heterogeneity, seasonality, and parameter complexity requirements. Q. J. R. Meteorol. Soc., 138, 1094-1113, doi:10.1002/qj.963.

Luhar, A.K., M. Thatcher, P.J. Hurley (2014) Evaluating a building-averaged urban 701 surface scheme in an operational mesoscale model for flow and dispersion, Atmos. $702 \quad$ Environ., 88, 47-58, doi:10.1016/j.atmosenv.2014.01.059.

703 Martilli A., A. Clappier, M.W. Rotach (2002), An urban surface exchange 704 parameterisation for mesoscale models. Boundary-Layer Meteorol, 104: 261-304. 705 Masson V. (2000) A physically-based scheme for the urban energy budget in 706 atmospheric models. Boundary-Layer Meteorol, 41: 1011-1026.

707 Masson V., C.S.B. Grimmond, T.R. Oke (2002), Evaluation of the Town Energy 708 Balance (TEB) scheme with direct measurements from dry districts in two cities. $J$ 709 Appl Meteorol, 41: 1011-1026.

710 McCarthy, M.P., M.J. Best, R.A. Betts (2010), Climate change in cities due to global 711 warming and urban effects, Geophys. Res. Letters, 37, L09705, 712 doi:10.1029/2010GL042845.

713 Offerle B., C.S.B. Grimmond, T.R. Oke (2003), Parameterization of net all-wave 714 radiation for urban areas. J Appl Meteorol, 42: 1157-1173.

715 Oke TR (2006) Towards better scientific communication in urban climate. Theor. 716 Appl. Climatol. 84: 179-190. doi: 10.1007/s00704-005-0153-0

717 Oleson, K.W., G.B. Bonan, J. Feddema, M. Vertenstein, C.S.B. Grimmond (2008a), 718 An urban parameterization for a global climate model: 1. Formulation and 719 evaluation for two cities, J. Appl. Meteorol. Climatol., 47, 1038-1060.

720 Oleson K.W., G.B. Bonan, J. Feddema, M. Vertenstein. 2008b. An urban 721 parameterization for a global climate model: 2. Sensitivity to input parameters and 
the simulated heat island in offline simulations. J Appl Meteorol Climatol, 47: $1061-1076$.

724

725

Oleson, K.W., G.B. Bonan, J. Feddema, T. Jackson (2011), An examination of urban heat island characteristics in a global climate model, Int. J. Climatol., 31, 18481865. doi:10.1002/joc.2201.

Pickett, S.T.A., M.L. Cadenasso, J.M. Grove, P.M. Groffman, L.E. Band, C.G. Boone, W.R. Burch, Jr., C.S.B. Grimmond, J. Hom, J.C. Jenkins, N.L. Law, C.H. Nilon, R.V. Pouyat, K. Szlavecz, P.S. Warren, M.A. Wilson. 2008. Beyond urban legends: an emerging framework of urban ecology, as illustrated by the Baltimore Ecosystem Study. BioScience. 58(2):139-150

Pigeon G., M.A. Moscicki, J.A. Voogt, V. Masson (2008), Simulation of fall and winter surface energy balance over a dense urban area using the TEB scheme. Meteorol Atmos Phys, 102: 159-171.

Porson A., P.A. Clark, I.N. Harman, M.J. Best, S.E. Belcher (2010), Implementation of a new urban energy budget scheme in the MetUM. Part II. Validation against observations and model intercomparison. Q J R Meteorol Soc, 136: 1530-1542.

Radhi, H., S. Sharples (2013), Quantifying the domestic electricity consumption for air-conditioning due to urban heat islands in hot arid regions, Applied Energy, 112, 371-380, doi:10.1016/j.apenergy.2013.06.013.

Ryu Y.-H., J.-J. Baik, S.-H. Lee (2011), A new single-layer urban canopy model for use in mesoscale atmospheric models. J Appl Meteorol Climatol, 50: 1773-1794. doi: 10.1175/2011JAMC2665.1

Ryu, Y.-H., J.J. Baik (2013), Effects of anthropogenic heat on ozone air quality in a megacity. Atmos. Environ., 80, 20-30, doi:10.1016/j.atmosenv.2013.07.053. 
746 Saha, M.V., R.E. Davis, D.M. Hondula (2014), Mortality displacement as a function

747 of heat event strength in 7 US cities, American J. Epidemiology, 179, 467-474, 748 doi:10.1093/aje/kwt264.

749 Sailor, D.J., L. Lu (2004), A top-down methodology for developing diurnal and 750 seasonal anthropogenic heating profiles for urban areas. Atmos. Environ., 38, $751 \quad$ 2737-2748, doi:10.1016/j.atmosenv.2004.01.034.

752 Salamanca F., E.S. Krayenhoff, A. Martilli (2009), On the derivation of material 753 thermal properties representative of heterogeneous urban neighbourhoods. J Appl $754 \quad$ Meteorol Climatol, 48: 1725-1732.

755 Salamanca F., A. Krpo, A. Martilli, A. Clappier (2010), A new building energy model 756 coupled with an urban canopy parameterization for urban climate simulations 757 part I. Formulation, verification, and sensitivity analysis of the model. Theor Appl $758 \quad$ Climatol, 99: 345-356. doi: 10.1007/s00704-009-0142-9.

759 Salamanca F., A. Martilli (2010), A new Building Energy Model coupled with an 760 Urban Canopy Parameterization for urban climate simulations - part II. Validation 761 with one dimension off-line simulations. Theor Appl Climatol, 99: 345-356.

762 Sarrat, C., A. Lemonsu, V. Masson, D. Guedalla (2006), Impact of urban heat island 763 on regional atmospheric pollution, Atmos. Environ., 40, 1743-1758, 764 doi:10.1016/j.atmosenv.2005.11.037.

765 Stewart, I.D., T.R. Oke (2012), Local climate zones for urban temperature studies, 766 Bull. American Meteorol. Soc., 93, 1879-1900, doi:10.1175/BAMS-D-11-00019.1. 
769 Figure 1: Conceptual figure of how surface energy balance exchanges are included in

770 urban land surface models of different complexity. Note individual models have

771 simple and complex features (Grimmond et al., 2011).

772

773 Figure 2: For each flux and physical category class (Table 4), the percentage of 774 modelled data points within the specified observational errors (eqn. 1) for Stages 1 775 and 4 (grey) plus the change relative to the previous stage (eqn. 2; scaled between $776100 \%$ and $100 \%$, shown by the horizontal dotted lines). Blue shading indicates an 777 improvement $(>0)$ and red degradation $(<0)$. Results are shown for day and night778 time (with day defined as incoming solar radiation flux greater than $0 \mathrm{~W} \mathrm{~m}^{-2}$ ). Codes 779 definition for the physical categories and component classes (used in the X-axis) are 780 given in Table 4

782 Figure 3: As for Fig. 2, but for the radiative fluxes

784 Figure 4: The subset of models within a class of a category improved compared to all models $\left(P_{c a}\right.$, eqn. 4) ranked according to the median over the stages (for each flux, by time of day (as for Fig. 2)). Shading shows the range of results over the stages, with the individual results shown as horizontal lines within this. The colouring emphasises

788 the values of the median over the stages, with $100 \%$ corresponding to all classes 789 improved, $0 \%$ all classes degraded and 50\% no change. Note X-axis code (Table 4) 790 order changes between subplots because of ranking (Colour text is to aid differences 791 to be noted). 
Table 1: Urban land surface models (ULSMs) used to obtain results that are analysed comparison.

\begin{tabular}{|c|c|}
\hline Model name & References \\
\hline Building effect parameterization (BEP) & $\begin{array}{l}\text { Martilli et al. (2002) Salamanca et al. }(2009,2010) \text {; } \\
\text { Salamanca and Martilli (2010) }\end{array}$ \\
\hline $\begin{array}{l}\text { Community Land Model - urban (CLM- } \\
\text { urban) }\end{array}$ & Oleson et al. (2008a, 2008b) \\
\hline $\begin{array}{l}\text { Institute of Industrial Science urban } \\
\text { canopy model }\end{array}$ & Kawamoto and Ooka $(2006,2009 a, 2009 b)$ \\
\hline $\begin{array}{l}\text { Joint UK land environment simulator } \\
\text { (JULES) }\end{array}$ & $\begin{array}{l}\text { Essery et al. (2003); Best (2005); Best et al. (2006); Best } \\
\text { et al. (2011) }\end{array}$ \\
\hline $\begin{array}{l}\text { Local-scale urban meteorological } \\
\text { parameterization scheme (LUMPS) }\end{array}$ & $\begin{array}{l}\text { Grimmond and Oke (2002); Offerle et al. (2003); Loridan } \\
\text { et al. (2011) }\end{array}$ \\
\hline $\begin{array}{l}\text { Met Office Reading urban surface } \\
\text { exchange scheme (MORUSES) }\end{array}$ & $\begin{array}{l}\text { Harman et al. (2004a, 2004b); Harman and Belcher } \\
\text { (2006), Porson et al. (2010) }\end{array}$ \\
\hline Multi-layer urban canopy model & Kondo and Liu (1998); Kondo et al. (2005) \\
\hline $\begin{array}{l}\text { National and Kapodistrian University of } \\
\text { Athens model }\end{array}$ & Dandou et al. (2005) \\
\hline $\begin{array}{l}\text { Noah land surface model/single-layer } \\
\text { urban canopy model }\end{array}$ & $\begin{array}{l}\text { Kusaka et al. (2001); Chen et al. (2004); Loridan et al. } \\
\text { (2010) }\end{array}$ \\
\hline $\begin{array}{l}\text { Seoul National University urban canopy } \\
\text { model }\end{array}$ & Ryu et al. (2011) \\
\hline $\begin{array}{l}\text { Simple urban energy balance model for } \\
\text { mesoscale simulation }\end{array}$ & Kanda et al. (2005a, 2005b); Kawai et al. $(2007,2009)$ \\
\hline Slab urban energy balance model & Fortuniak (2003); Fortuniak et al. $(2004,2005)$ \\
\hline $\begin{array}{l}\text { Soil model for submesoscales } \\
\text { (urbanized) }\end{array}$ & Duport and Mestayer (2006); Dupont et al. (2006) \\
\hline Temperatures of urban facets (TUF) & Krayenhoff and Voogt (2007) \\
\hline Town energy balance (TEB) & $\begin{array}{l}\text { Masson (2000); Masson et al. (2002); Lemonsu et al. } \\
\text { (2004); Pigeon et al. (2008), Hamdi and Masson (2008) }\end{array}$ \\
\hline Vegetated urban canopy model & Lee and Park (2008) \\
\hline
\end{tabular}


Table 2: Methods used to obtain the observed fluxes used for comparison with the ULSM. Sources: Coutts et al., (2007a, 2007b). Height of observation for all fluxes: 40 m.

\begin{tabular}{|c|c|c|c|}
\hline Flux & Instrument / Method & $\begin{array}{l}\text { Sampling } \\
\text { frequency }(\mathrm{Hz} .)\end{array}$ & Averaging period (min) \\
\hline $\begin{array}{l}S W_{u p} \\
L W_{u p} \\
Q^{*}\end{array}$ & Kipp and Zonen CM7B and CG4 radiometers & 1 & 30 \\
\hline$Q_{H}$ & CSI CSAT 3D sonic anemometer & 10 & 30 \\
\hline$Q_{E}$ & $\begin{array}{l}\text { CSI CSAT 3D sonic anemometer } \\
\text { CSI Krypton hygrometer (Aug } 2003-\text { Feb } \\
\text { 2004), } \\
\text { LiCOR LI7500 open-path infrared gas } \\
\text { analyser (remaining period) }\end{array}$ & 10 & 30 \\
\hline$\Delta Q_{S}$ & Residual of the surface energy balance & N/A & 30 \\
\hline$Q_{F}$ & $\begin{array}{l}\text { Calculated (Sailor and Lu,2004) : } \\
\text { Vehicles: Numbers from survey (Nov. } 2002- \\
\text { Oct } 2003 \\
\text { Building sector: } 30 \text { min electricity and daily } \\
\text { natural gas statistics } \\
\text { Human metabolism: Night, day and transition } \\
\text { period metabolic rates, with population } \\
\text { density statistics }\end{array}$ & N/A & $\begin{array}{l}\text { Average monthly } \\
\text { diurnal cycle at } 30 \mathrm{~min} . \\
\text { resolution }\end{array}$ \\
\hline
\end{tabular}

804 
Table 3. Information released at each stage of the comparison

\begin{tabular}{|l|l|}
\hline Stage & \begin{tabular}{l} 
Information released \\
\hline 1
\end{tabular} \\
& $\begin{array}{l}\text { Atmospheric forcing data only } \\
\text { wind speed, temperature, specific humidity and surface pressure) }\end{array}$ \\
\hline 2 & $\begin{array}{l}\text { Vegetation and built fractions } \\
\text { (Building heights, height-to-width ratio, mean wall to plan area ratio, fraction of surface } \\
\text { covered by buildings, concrete, road, })\end{array}$ \\
\hline 4 & $\begin{array}{l}\text { Specific information on building materials } \\
\text { (e.g., albedo and thermal properties of wall, road, roof) }\end{array}$ \\
\hline 5 & $\begin{array}{l}\text { Observed fluxes for parameter optimisation } \\
\text { (Not considered in this study) }\end{array}$ \\
\hline
\end{tabular}



2011 for more details). Colours are used on the plots to aid comparison.

\begin{tabular}{|c|c|c|c|}
\hline Category & & & Class \\
\hline Vegetation (V) & None (n) & Separate tile (s) & Integrated (i) \\
\hline No. of models & 8 & 19 & 5 \\
\hline $\begin{array}{c}\text { Anthropogenic heat flux } \\
\qquad\left(A_{N}\right)\end{array}$ & None (n) & $\begin{array}{l}\text { Prescribed flux } \\
\text { (p) }\end{array}$ & $\begin{array}{c:c}\text { Internal building } & \text { Modelled (m) } \\
\text { temperature (i) } & \end{array}$ \\
\hline No. of models & 22 & 2 & 2 \\
\hline $\begin{array}{c}\text { Temporal variation of } \\
\text { the anthropogenic heat } \\
\text { flux (T) }\end{array}$ & $\begin{array}{l}\text { None (i.e., } \\
\text { no flux) } \\
\text { (n) }\end{array}$ & $\begin{array}{l}\text { Fixed (i.e., time } \\
\text { invariant flux) } \\
\text { (f) }\end{array}$ & $\begin{array}{l}\text { Variable (i.e., time varying flux) } \\
\text { (v) }\end{array}$ \\
\hline No. of models & 22 & 3 & 7 \\
\hline Urban morphology (L) & Bulk (1) & Single layer (2) & Multiple layer (4) \\
\hline No. of models & 6 & 20 & 6 \\
\hline Facets \& orientation $\left(\mathrm{F}_{0}\right)$ & Bulk (1) & $\begin{array}{l}\text { Roof, walls, road } \\
\text { without } \\
\text { orientation (n) }\end{array}$ & \begin{tabular}{c|c} 
Roof, walls, road & Roof, walls, road \\
with orientation, & with orientation \\
no intersections & and intersections \\
(o) & (i)
\end{tabular} \\
\hline No. of models & 5 & 17 & 6 \\
\hline Reflections (R) & Single (1) & Multiple (m) & Infinite (i) \\
\hline No. of models & 11 & 13 & 8 \\
\hline Albedo, emissivity $\left(\mathrm{A}_{\mathrm{E}}\right)$ & Bulk (1) & Two facet (2) & Three facet (3) \\
\hline No. of models & 5 & 4 & 23 \\
\hline Net storage heat flux (S) & $\begin{array}{l}\text { Net all } \\
\text { wave } \\
\text { radiation } \\
\text { (n) }\end{array}$ & $\begin{array}{l}\text { Surface energy } \\
\text { balance residual } \\
\text { (r) }\end{array}$ & Conduction equation (c) \\
\hline No. of models & 3 & 6 & 23 \\
\hline
\end{tabular}


Simple models
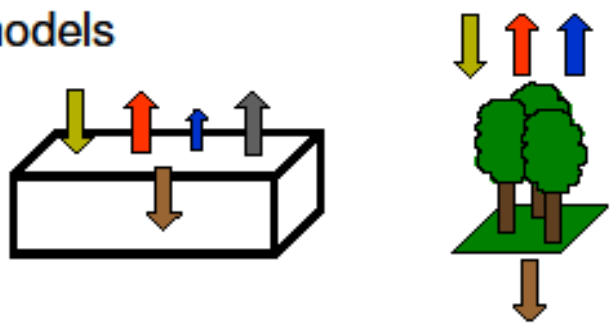

Moderate complexity models
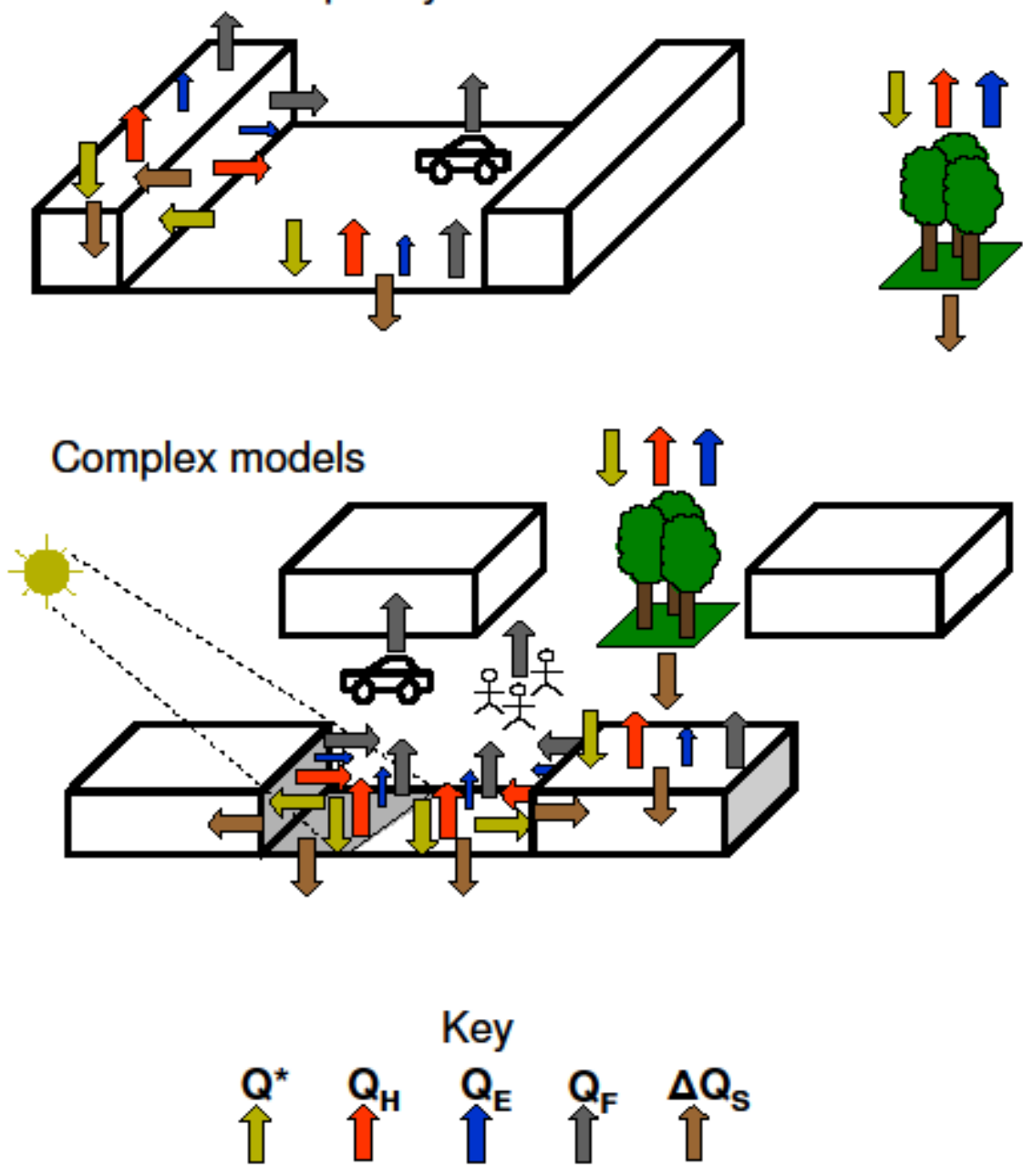

814 Figure 1: Conceptual figure of how surface energy balance exchanges are included in urban land surface models of different complexity. Note individual models have

816 simple and complex features (Grimmond et al., 2011). 

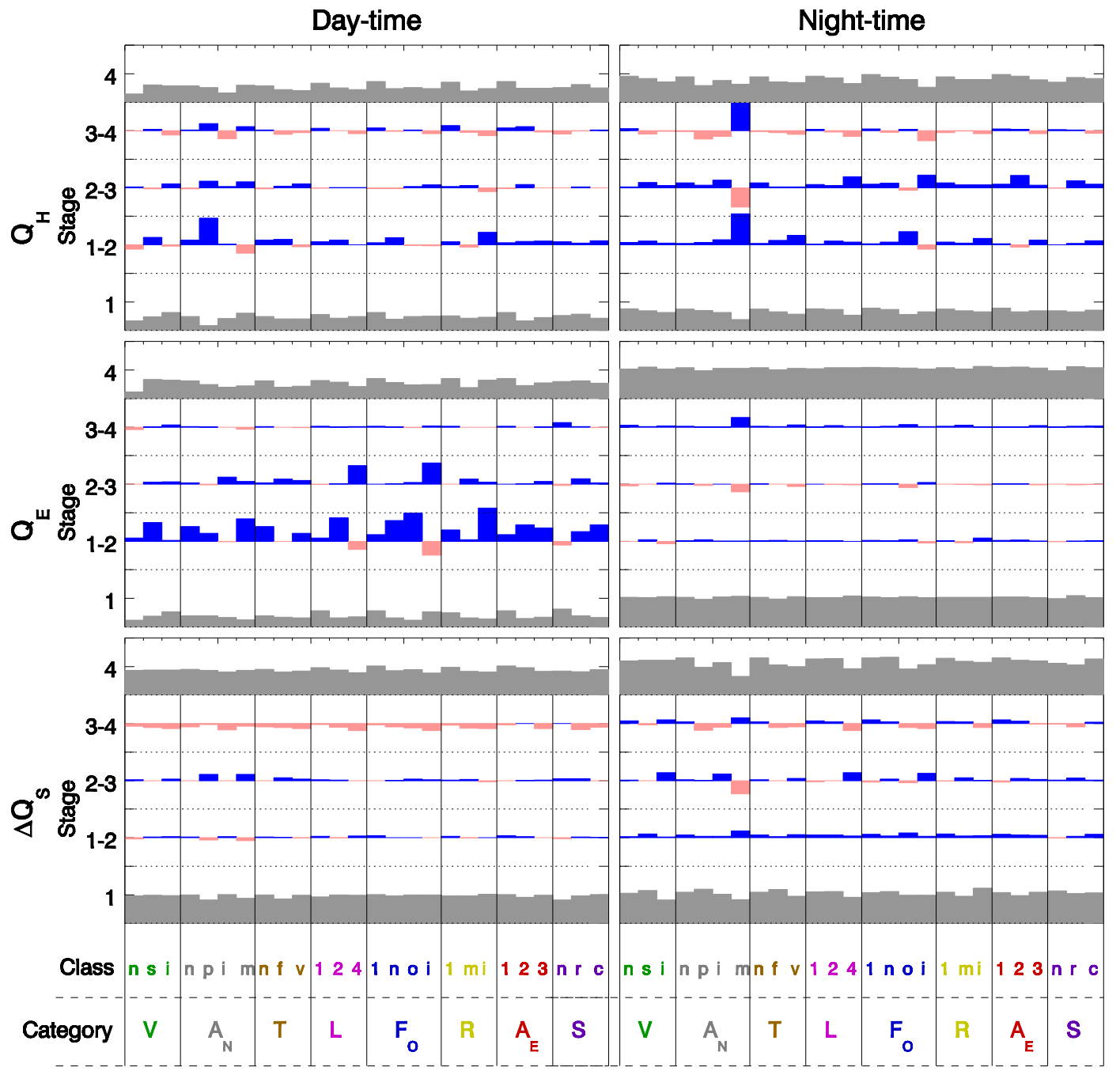

819 Figure 2: For each flux and physical category class (Table 4), the percentage of

820 modelled data points within the specified observational errors (eqn. 1) for Stages 1

821 and 4 (grey) plus the change relative to the previous stage (eqn. 2; scaled between

$822-100 \%$ and $100 \%$, shown by the horizontal dotted lines). Blue shading indicates an

823 improvement $(>0)$ and red degradation $(<0)$. Results are shown for day and

824 night-time (with day defined as incoming solar radiation flux greater than $0 \mathrm{~W} \mathrm{~m}^{-}$

$825{ }^{2}$ ). Codes definition for the physical categories and component classes (used in the $826 \quad \mathrm{x}$-axis) are given in Table 4. 


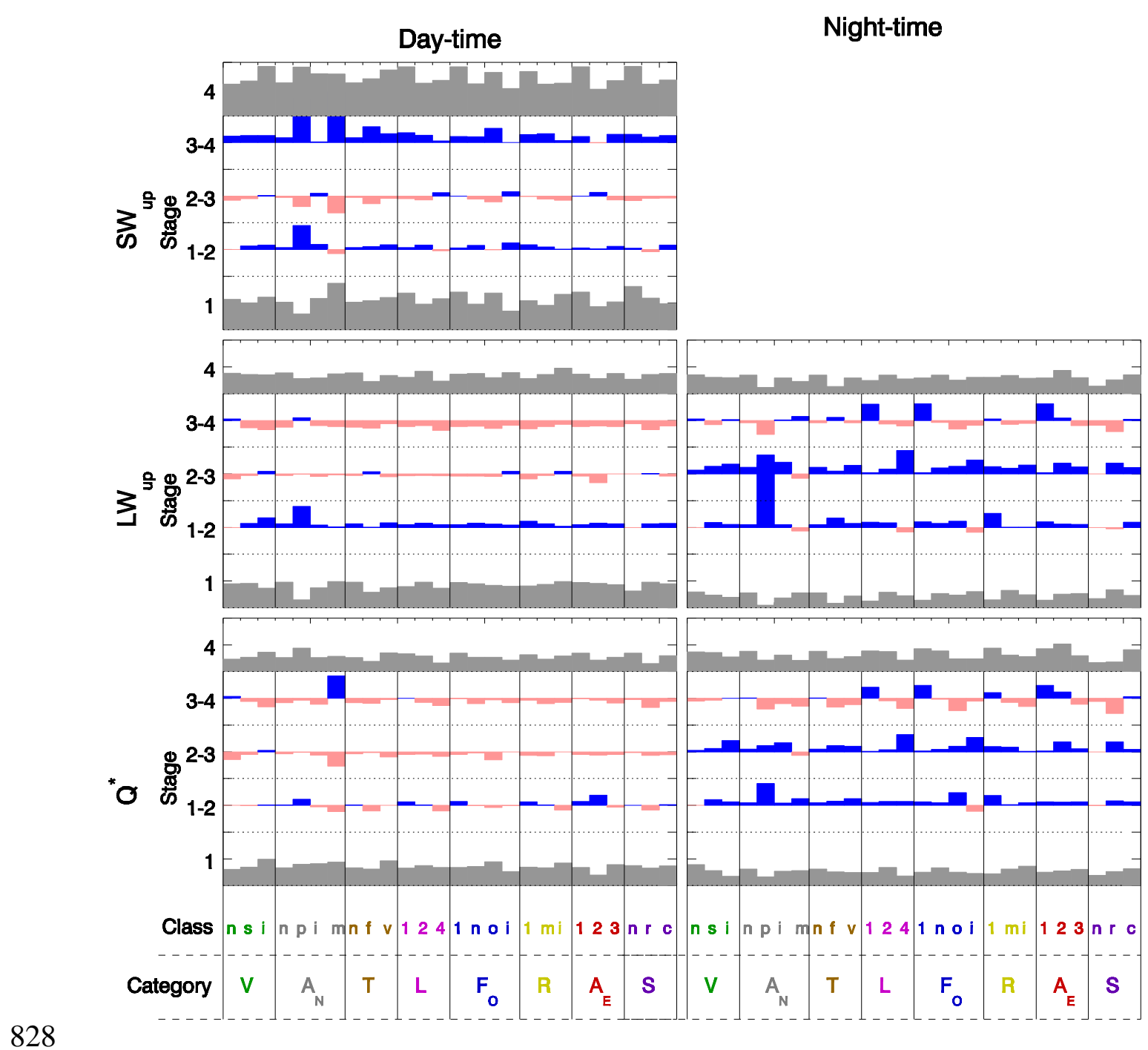

829 Figure 3: As for Fig. 2, but for the radiative fluxes. 

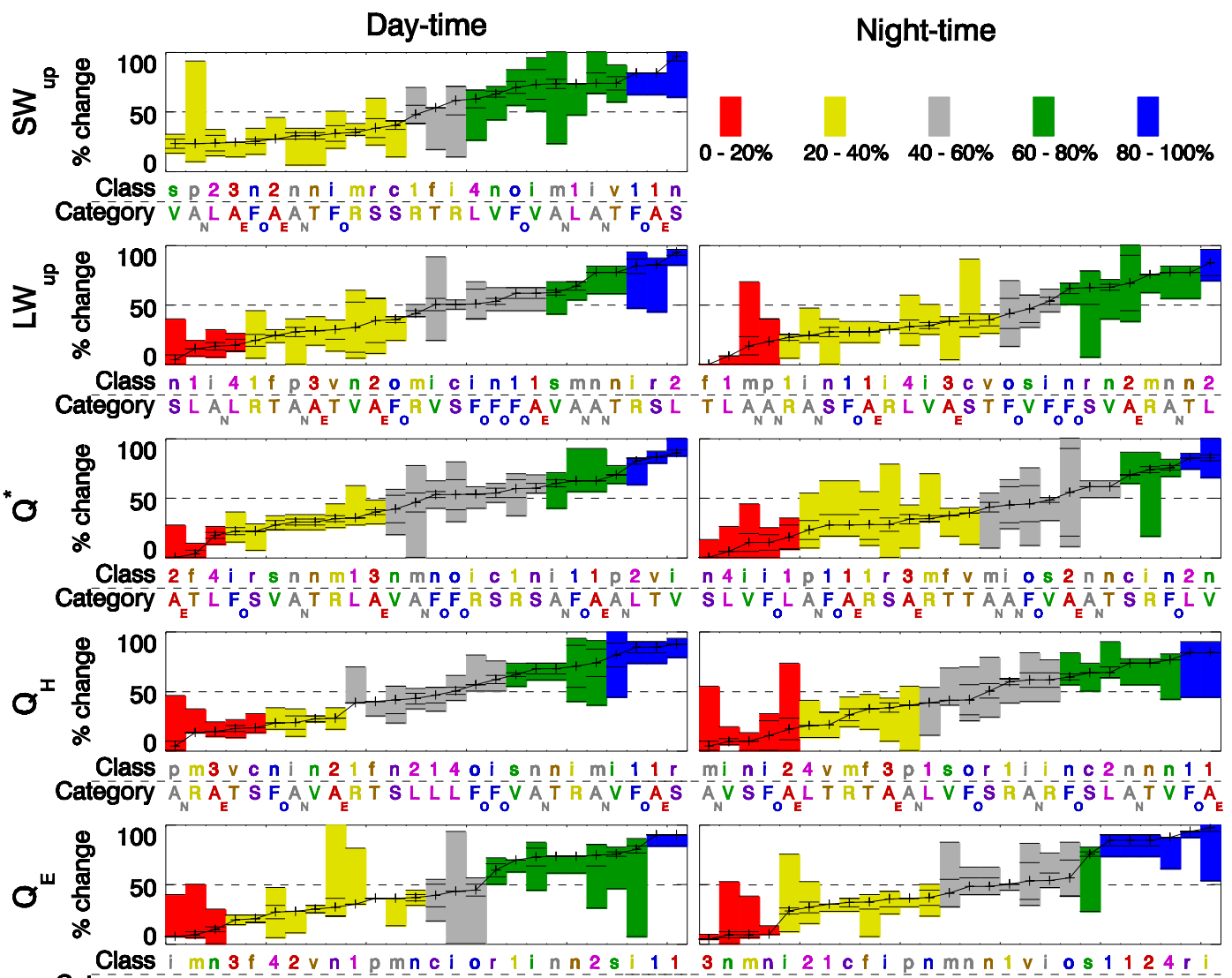

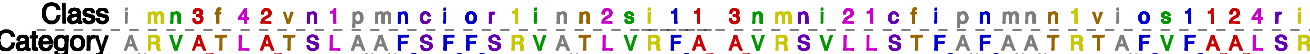

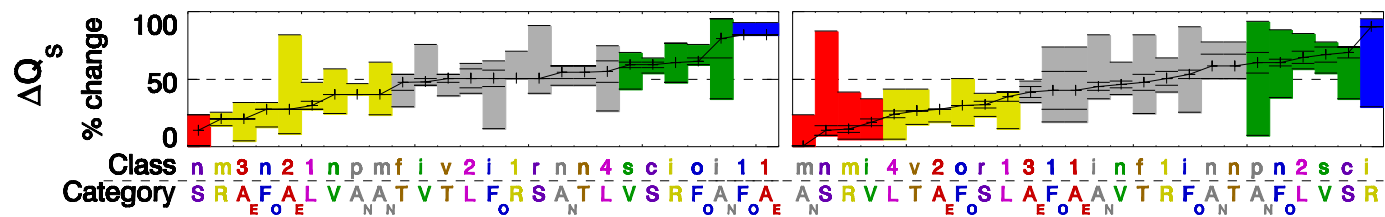

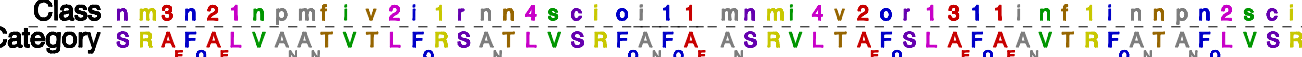

832 Figure 4: The subset of models within a class of a category improved compared to all

833 models $\left(P_{c a}\right.$, eqn. 4) ranked according to the median over the stages (for each flux,

834 by time of day (as for Fig. 2)). Shading shows the range of results over the stages,

835 with the individual results shown as horizontal lines within this. The colouring

836 emphasises the values of the median over the stages, with $100 \%$ corresponding to

837 all classes improved, $0 \%$ all classes degraded and $50 \%$ no change. Note $\mathrm{X}$-axis

838 code (Table 4) order changes between subplots because of ranking (Colour text is

839 to aid differences to be noted). 